Article

\title{
Regional Water Balance Based on Remotely Sensed Evapotranspiration and Irrigation: An Assessment of the Haihe Plain, China
}

\author{
Yanmin Yang ${ }^{1}$, Yonghui Yang ${ }^{1, *}$, De Li Liu ${ }^{2,3}$, Tom Nordblom ${ }^{2,3}$, Bingfang Wu ${ }^{4}$ \\ and Nana Yan ${ }^{4}$
}

1 Key Laboratory of Agricultural Water Resources, Center for Agricultural Resources Research, Institute of Genetics and Developmental Biology, Chinese Academy of Sciences, 286 Huaizhong Road, Shijiazhuang 050020, China; E-Mail: ymyang@ sjziam.ac.cn

2 EH Graham Centre for Agricultural Innovation, Wagga Wagga, New South Wales 2650, Australia; E-Mails: de.li.liu@dpi.nsw.gov.au (D.L); Tom.nordblom@industry.nsw.gov.au (T.N.)

3 NSW Department of Primary Industry, Wagga Wagga Agricultural Institute, Pine Gully Road, Wagga Wagga, NSW 2650, Australia

4 Key Lab. Of Digital Earth Sciences, Institute of Remote Sensing and Digital Earth Chinese Academy of Science, P.O. Box 9718, No. 20, Datun Road, Olympic Science Park, Beijing 100101, China; E-Mails: wubf@radi.ac.cn (B.W.); yannn@radi.ac.cn (N.Y.)

* Author to whom correspondence should be addressed; E-Mail: yonghui.yang@ @jziam.ac.cn; Tel.: +86-311-8581-4368.

Received: 6 January 2014; in revised form: 12 March 2014 / Accepted: 13 March 2014 /

Published: 20 March 2014

\begin{abstract}
Optimal planning and management of the limited water resources for maximum productivity in agriculture requires quantifying the irrigation applied at a regional scale. However, most efforts involving remote sensing applications in assessing large-scale irrigation applied (IA) have focused on supplying spatial variables for crop models or studying evapotranspiration (ET) inversions, rather than directly building a remote sensing data-based model to estimate IA. In this study, based on remote sensing data, an IA estimation model together with an ET calculation model (ETWatch) is set up to simulate the spatial distribution of IA in the Haihe Plain of northern China. We have verified this as an effective approach for the simulation of regional IA, being more reflective of regional characteristics and of higher resolution compared to single site-specific results. The results show that annual ET varies from $527 \mathrm{~mm}$ to $679 \mathrm{~mm}$ and IA varies from $166 \mathrm{~mm}$ to
\end{abstract}


$289 \mathrm{~mm}$, with average values of $602 \mathrm{~mm}$ and $225 \mathrm{~mm}$, respectively, from 2002 to 2007. We confirm that the region along the Taihang Mountain in Hebei Plain has serious water resource sustainability problems, even while receiving water from the South-North Water Transfer (SNWT) project. This is due to the region's intensive agricultural production and declining groundwater tables. Water-saving technologies, including more timely and accurate geo-specific IA assessments, may help reduce this threat.

Keywords: ETWatch; remote sensing technique; ET; irrigation requirement

\section{Introduction}

Competition for water resources in agriculture is increasing with water scarcity and becoming more serious in the 21 st century. The agricultural sector is one of the biggest consumers of water resources, accounting for more than $70 \%$ of the world's fresh water use from rivers and groundwater [1]. This figure is even greater in Asia and the Pacific region, where it accounts for as much as 90\% [1]. For optimal planning and management of the limited water resources for maximum crop productivity in agriculture, especially in arid and semi-arid regions of the world, techniques are required to quantify the irrigation applied (IA) at regional scales.

Haihe Basin, located in North China, has especially severe water shortage problems. However, this basin undertakes the heavy task of grain production to support a large proportion of the Chinese population of this area. To sustain high-yield grain production, irrigation demand has been satisfied by excessive groundwater pumping, which has caused sharply declining groundwater tables. To alleviate water shortage problems in North China, the South-North Water Transfer (SNWT) project is under construction. The transferred water will be mainly used to meet high priority domestic and industrial demands. However, a large amount of surface water will then be released for agricultural use. The problem of how to redistribute water among different sectors and how much will be available for agricultural use will emerge with the completion of the project. Thus, the ability to accurately assess the spatial distribution of irrigation demand is necessary.

The science of assessing IA on larger regional scales has undergone development from a focus on statistical data to the present combination of techniques of crop growth simulation, a geographical information system (GIS) and remote sensing [2]. Early methods applied to assess irrigation requirements include water metering, questionnaires, water use coefficients, water rights, pumping hours or electricity consumption [2]. For example, Boken et al. [3] used irrigation requirements (mm) for cotton, peanut and maize measured at a limited number of sample sites combined with GIS and geospatial techniques to estimate regional water use at a county level in Georgia. These methods are direct and can be quite accurate, but are laborious and lacking in predictive capacity. Model-based estimation for IA has been reported in many documents, mainly including the Food and Agriculture Organization (FAO) Penman-Monteith method combining soil water balance models and crop growth simulation models.

The FAO Penman-Monteith method [4] has been widely used to estimate IA. The method is the internationally recommended standard for evapotranspiration (ET) estimation in both humid and arid 
environments [5]. Ozdogan et al. [6] used the CROPWAT system (S) (a computer program for irrigation planning and management) to estimate water use in south-eastern Turkey, which computes Penman-Monteith-based reference (potential) evapotranspiration (ETp) and then adjusts this generalized variable for each crop using seasonal growth curves, or so-called Kc parameters. Leenhardt et al. [7] applied a simulation platform called ADEAUMIS (an irrigation water demand assessment tool), which mainly includes the FAO Penman-Monteith method and a spatial database to estimate IA. However, FAO guidelines are often used to estimate crop evapotranspiration from observed or standard values of crop development [7].

Crop models that dynamically simulate plant growth and the water demand of one or several crops can provide quantitative contributions to the environmental impact assessment and be very useful for water management [7]. One of the limitations of current crop simulation models is that they are site specific. By combining with spatial data, crop models have been used by many scientists to estimate IA at regional or global scales. Ines et al. [8] applied crop simulation models CERES-rice (Crop Environment Resource Synthesis for rice), CERES-maize and CROPGRO-peanut (a process-oriented model for crop growth of peanut) in DSSAT (Decision Support System for Agrotechnology Transfer) version 3.0 coupled with GIS to the estimate irrigation needs for rice, maize and peanut, and then water productivity in the Laoag River Basin in Ilocos Norte, Philippines. The cropping system model, CROPGRO-Cotton, combined with kriging interpolation, was used to evaluate the spatial distribution of monthly irrigation water use for cotton in the Coastal Plain region of Georgia [9]. Wriedt et al. [2] estimated the spatial distribution of irrigation applied at a $10 \times 10-\mathrm{km}$ grid resolution in Europe with the crop growth model, EPIC (Erosion Productivity Impact Calculator), combining available regional statistics on crop distribution, crop-specific irrigated area and spatial data sources on soils, land use and climate. The global scale water use of wheat was estimated by combining EPIC with GIS (geographic information system) [10].

The shortage of geo-located data on agricultural practices was considered to be a limiting factor for the operational use of crop models over large scales [11]. Fortunately, public domain Internet satellite data and scientific development make remote sensing an attractive option for assessing irrigation performance from individual fields to scheme or river basin scale [1]. One of the applications of remote sensing in assessing irrigation performance is in providing information on some key variables of crop production and, especially, variations in these over time and space. For example, Ozdogan et al. [6] successfully estimated irrigated area with the aid of remote sensing to compute water use in south-eastern Turkey, in the period 1993 to 2002. Ines et al. [12] estimated the distributed data, e.g., sowing dates, irrigation practices, soil properties, depth to groundwater and water quality, required as inputs to regional modelling by minimizing the residuals between the distributions of field-scale ET simulated by regional application of the SWAP (Soil, Water, Atmosphere and Plant) model and by the surface energy balance algorithm for land (SEBAL) using pairs of Landsat-7 ETM+ images. Another application of remote sensing in assessing irrigation performance was to estimate ET. The satellite-based model SEBAL has been applied in more than 30 countries worldwide and is now an operational instrument for targeting, monitoring and evaluating irrigation and drainage systems [13]. ETWatch is another ET monitoring system using remote sensing, which integrates SEBAL and SEBS and is commonly used in North China [14]. 
As stated above, most documents on RS applications for assessing irrigation water applied at larger scales focused on providing spatial variables for crop models or studies on ET inversion. Little literature is available on directly using RS to determine irrigation water requirements. The objectives of the present study are to: (1) set up a model based on RS-based ETWatch and a soil water balance model to evaluate irrigation water requirements; (2) analyse the spatial distribution of IA to evaluate regional water sustainability.

\section{Study Area}

The Haihe Plain $\left(112-118^{\circ} \mathrm{E}, 35-42^{\circ} \mathrm{N}\right)$ is selected for this study. Located in the northern part of China, it is one of the three parts of the North China Plain, with an approximate area of $131,000 \mathrm{~km}^{2}$ [15]. There are five administrative regions in this catchment, including Beijing, Tianjin, most of Hebei Province and the northern parts of Shangdong and Henan Provinces (Figure 1). This area has a moderate temperate, semi-arid and sub-humid climate. Long-term annual mean air temperature in the catchment ranges from $1.5{ }^{\circ} \mathrm{C}-14{ }^{\circ} \mathrm{C}$ and annual mean precipitation is $535 \mathrm{~mm}$ (84\% occurring between June and September). Haihe Catchment is one of the most important grain production areas in China, accounting for about $10 \%$ of the nation's total. The catchment contains $11 \%$ of the arable land to support $10 \%$ of China's population. However, the Catchment only has $1.3 \%$ of the national water resources. Long-term average annual water resource volume is 37.2 billion $\mathrm{m}^{3}$ $\left(37.2 \mathrm{~km}^{3}\right)$, and water resources per capita are only $305 \mathrm{~m}^{3}, 14 \%$ of the national average level and $3.7 \%$ of the world average [16]. Water resources in Haihe Catchment are the lowest among the seven biggest catchments in China.

Figure 1. Location of study area, the Haihe plain.

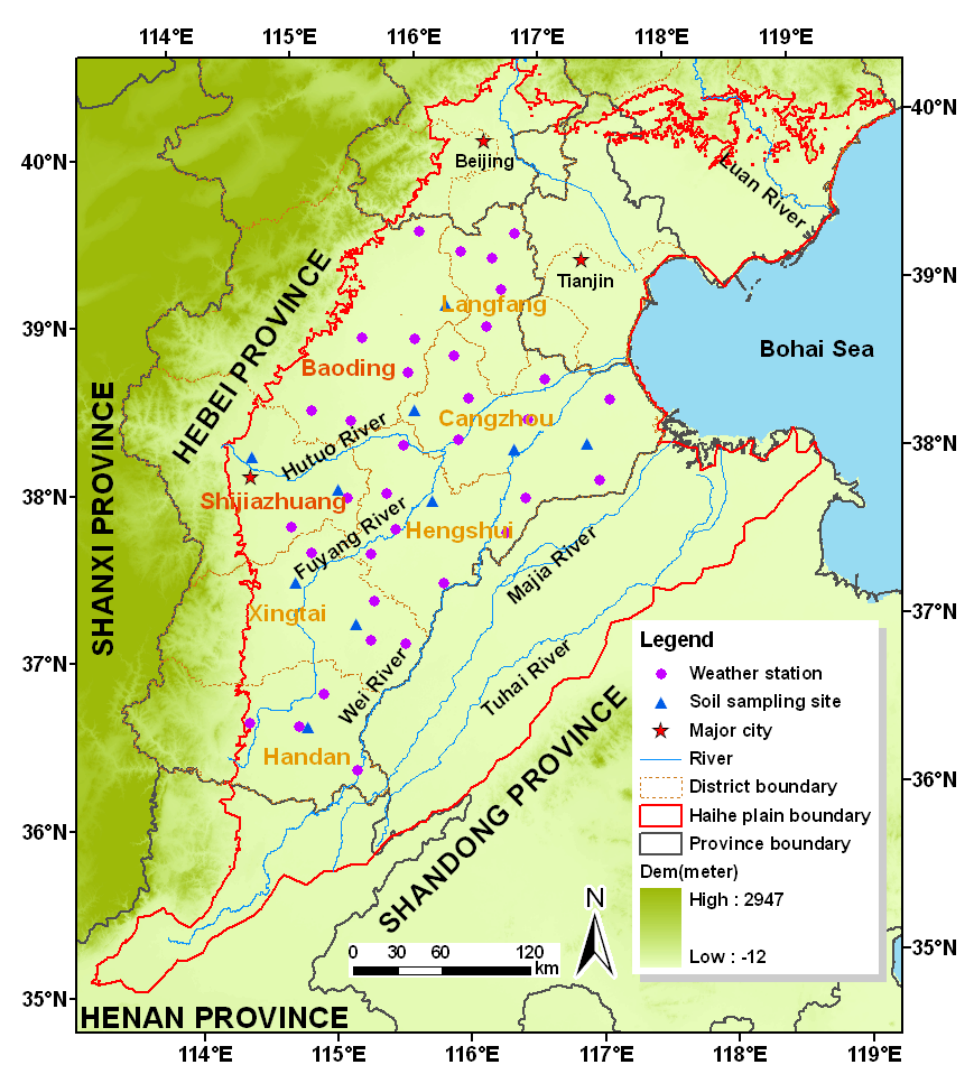


There is 8.0 million hectares of arable land in the Haihe Plain. Agriculture in this area is characterized by a diverse cropping pattern of winter wheat, corn, millet, sorghum, rice, soybean, cotton, potato, sweet potato and a variety of horticultural crops. Winter wheat-summer corn is the most important crop rotation system. As winter wheat grows in the dry season (sown in early October and harvested in early June in the next year), it is the biggest irrigation consumer. Some crops sown in the spring, such as spring corn, millet and cotton, are the second greatest irrigation users. These differ from the summer crops, which grow during the monsoon and only require supplementary irrigation to fill the gap when there is a shortage of precipitation. Planted areas of horticulture crops, such as vegetables and fruit trees, are increasing; becoming a larger potential irrigation user, because they commonly need more water per hectare than annual crops.

In Haihe Plain, $70 \%$ of irrigation water is sourced by groundwater pumping. Intensive use of groundwater has resulted in sharp declines in groundwater levels. The biggest groundwater drawdowns in the world are located in this area. This phenomenon has triggered severe environmental issues, such as land subsidence, aquifer compression and sea water intrusion [17]).

\section{Model Description}

\subsection{ETWatch}

ETWatch is an ET monitoring system using remote sensing. A brief description of ETWatch and an application for monitoring regional evapotranspiration were reported by $\mathrm{Wu}$ et al. [14]. ETWatch integrates SEBAL and SEBS to estimate surface fluxes under clear-sky conditions together with the Penman-Monteith approach to calculate daily ET, based on a surface resistance model, meteorological data and surface parameters from remote sensing. A brief description of ETWatch is given in the following text, and the main procedure is demonstrated in Figure 2.

The SEBAL model uses the following formula to convert global radiation into net radiation on a daily scale (Bastiaanssen et al. 2005 [13]),

$$
R_{n 24}=\tau\left(\left(1-r_{o}\right) R_{e x 24}-110\right)
$$

where $\tau=R_{24} / R_{\text {ex24 }}$, which accounts for the fraction of daily incoming solar radiation $\left(R_{24}\right)$ $\left(\mathrm{MJ} \cdot \mathrm{m}^{-2} \cdot \mathrm{day}^{-1}\right)$ to the extra-terrestrial solar radiation $\left(R_{e x 24}\right)\left(\mathrm{MJ} \cdot \mathrm{m}^{-2} \cdot \mathrm{day}^{-1}\right)$, and $\mathrm{r}_{0}$ is the surface albedo.

The parameter, $\rho$, measures the daily total atmospheric transmittance of extra-terrestrial solar radiation. The incoming solar radiation can be directly measured by pyranometers, but the availability of such data is limited, particularly in temporal and spatial contexts. ETWatch uses sunshine hours to compute $\rho$ as:

$$
\rho_{s w}=a_{s}+b_{s} \frac{n}{N}
$$

where $n$ is the sunshine hours for the day, $N$ is the maximum hours of sunshine on a typical cloud-free day, while $a_{\mathrm{s}}$ and $b_{\mathrm{s}}$ are empirical coefficients determined by regression analysis for daily data from weather stations in Haihe Catchment [18]. The parameters are determined separately for December-February (winter dry season) and March-November (wet season). 
Figure 2. Operational flow-chart of ETWatch for the monitoring and estimation of evapotranspiration (ET) (adapted after Wu et al. [14,19]). SEBAL, surface energy balance algorithm for land.

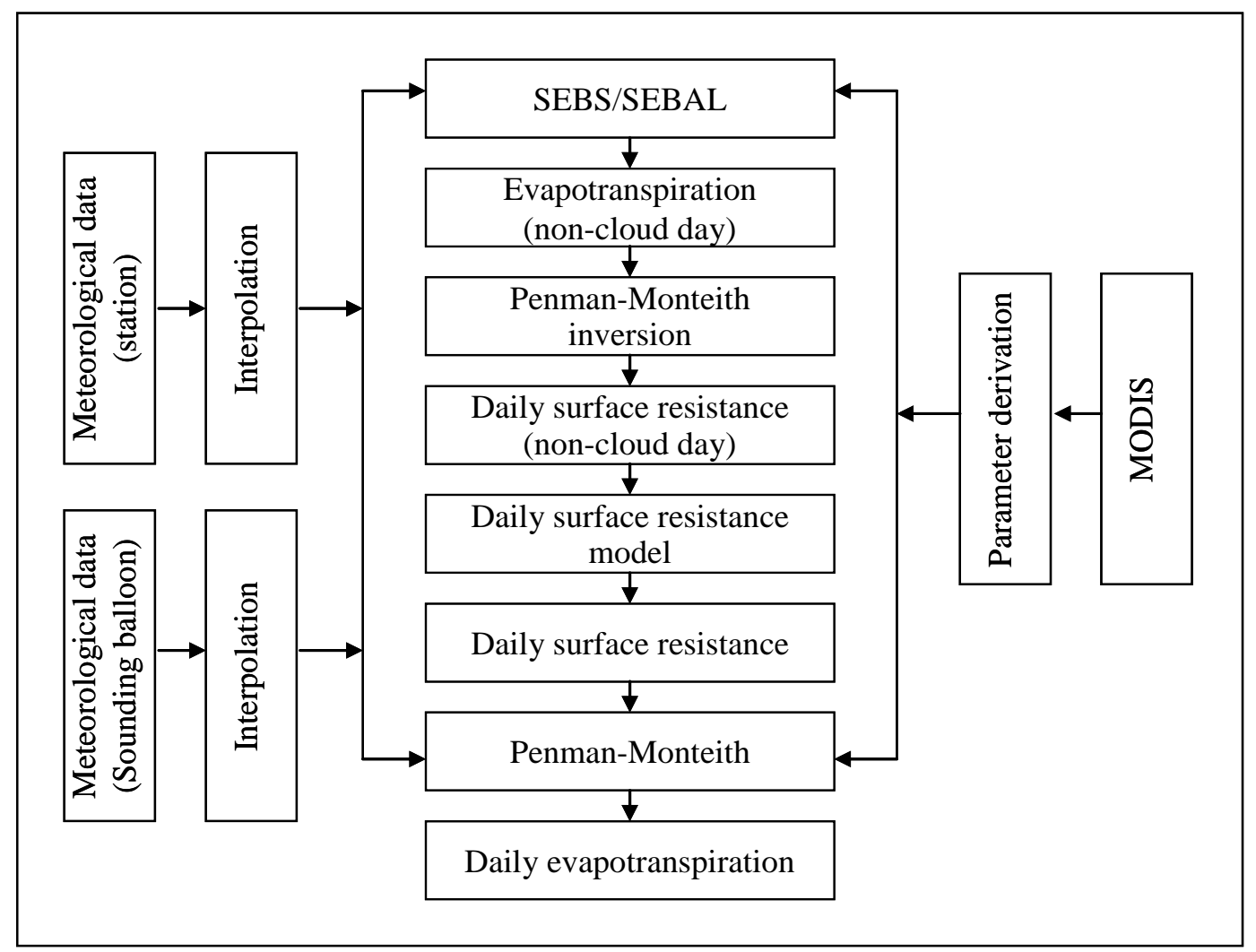

Momentum roughness $\left(Z_{o m}\right)$ is an important parameter for calculating energy balance. ET models were developed based generally on smooth surfaces that only take into account the influence of vegetation height on roughness or use empirical values linked to land use classifications. However, this approach performs poorly in hilly land. ETWatch calculates the roughness length, based on land cover by vegetation or non-vegetation and hypsography. The roughness length of the land covered by vegetation, $Z_{o m}{ }^{v}$, is calculated as a function of the normalized difference vegetation index (NDVI) as follows,

$$
Z_{o m}^{v}=0.001+\left(0.5 \frac{N D V I}{N D V I_{\text {max }}-N D V I_{\text {min }}}\right)^{2.5}
$$

where $N D V I=\left(\rho_{N I R}-\rho_{R E D}\right) /\left(\rho_{N I R}+\rho_{R E D}\right)$ and $\rho_{N I R}$ and $\rho_{R E D}$ are the near-infrared and infrared band reflectivities. $N D V I_{\min }$ and $N D V I_{\max }$ are the minimum and maximum vegetation indices in the region. The effect of topography and slope on surface roughness is then estimated as:

$$
Z_{o m}^{T}=Z_{o m}^{v}\left(1+\frac{\text { slope }-a}{b}\right)
$$

where $Z_{o m}{ }^{T}$ is the surface roughness length for topography, $a$ and $b$ are empirical coefficients and slope stands for topographic slope, which can be obtained from a digital terrain map. The surface roughness of the non-vegetation is computed from the surface geometric roughness derived from radar images: 


$$
\log \left(Z_{o m}^{r}\right)=-1.221+0.0906\left(\sigma_{o}\right)
$$

where $Z_{o m}{ }^{r}$ is the surface roughness of the non-vegetation fraction of the basin and $\sigma_{o}$ is the backscatter coefficient acquired from the Radarsat satellite image. The total basin roughness is finally computed as:

$$
Z_{o m}=w_{1} Z_{o m}^{v}+w_{2} Z_{o m}^{T}+w_{3} Z_{o m}^{r}
$$

where $w_{1}, w_{2}$ and $w_{3}$ are the weighted factors for vegetation, topography and bare-land on surface roughness. The values of $w_{1}, w_{2}$ and $w_{3}$ are $1.0,1.0$ and 0.25 , respectively for the Hai Basin, which were determined by using the empirical fitted ways [18].

Resistance for the days with clouds $\left(R S_{u n c}\right)$ is computed as:

$$
R S_{u n c}=\frac{L A I_{c l r} R S_{c l r}}{L A I_{u n c} m\left(T_{\min }\right) m(V P D)}
$$

where $R S_{c l r}$ is the resistance for the cloudless day, $\mathrm{LAI}_{u n c}$ is the leaf area index for the day with clouds, $\mathrm{LAI}_{c l r}$ is the leaf area index for cloud-free day and $m\left(T_{\min }\right)$ and $m(V P D)$ are the functions of minimum temperatures and vapour pressures, respectively, which account for the effect of extreme temperature and moisture on plant stomata.

\subsection{Irrigation Applied (IA) Estimation Model}

The sequence of calculations used to estimate IA is given in Figure 3. The model starts from the date when a crop is sown. Several practical assumptions are made. The initial soil water content is set as $60 \%$ of maximum plant available water $\left(\mathrm{SW}_{\mathrm{pa}}\right)$, which is generally used by farmers for crops to be sown. The depth of soil profile is set as $80 \mathrm{~cm}$. When soil water content is less than $40 \% \mathrm{SW}_{\mathrm{pa}}$, irrigation operation is to be triggered. The irrigation applied is equal to the difference between field capacity $\left(\mathrm{SW}_{\mathrm{fc}}\right)$ and the soil water content on the previous day $\left(\mathrm{SW}_{\mathrm{i}-1}\right)$. When there is precipitation on the day and the soil water content is greater than field capacity, the amount of water in excess of field capacity is assumed to go to deep drainage, and the current soil water content is set equal to field capacity. Since farmland in the Haihe Plain is very flat and soils are deep, there is a large water holding capacity, especially in relation to precipitation shortages; runoff $\left(\mathrm{RO}_{\mathrm{i}}\right)$ is minimal and may be ignored [20].

Water content at field capacity and permanent wilting point $\left(\mathrm{SW}_{\mathrm{fc}}\right.$ and $\left.\mathrm{SW}_{\mathrm{wp}}\right)$ are calculated by the SPAW model [21]) using the basic soil texture parameters, including clay content (\%), sand content (\%) and organic matter content $(\%)$. These soil parameters come from 76 representative sites in Haihe Catchment. Precipitation data are collected from 46 meteorological stations. All these data are finally interpolated into a $1-\mathrm{km}^{2}$ grid and prepared for use in the above-mentioned spatial calculation procedures.

\section{Data Collection}

\subsection{Remote Sensing Data}

The MODIS data used in this study are the MOD021KM, MOD02QKM, MOD02HKM and MOD03 products provided by the NASA Goddard Space Flight Center (GSFC) Level 1 and Atmosphere Archive and Distribution System (LAADS) [22]. The MOD02QKM and MOD02HKM products, including the $250-\mathrm{m}$ and $500-\mathrm{m}$ resolution bands, are aggregated to $1-\mathrm{km}$ resolution TOA 
(top of atmosphere) radiances and reflectance. The MOD03 products are the geolocation field data calculated for each 1-km MODIS Instantaneous Field of View (IFOV) for all daytime orbits. The geolocation fields include geodetic latitude, longitude, surface height above geoid, solar zenith and azimuth angles, satellite zenith and azimuth angles and a land/sea mask for each 1-km sample. The solar zenith and azimuth angles, satellite zenith and azimuth angles are used to estimate net shortwave radiation in this study. The MODIS 2.1- $\mu \mathrm{m}$ band was used for the detection of dark targets, estimating their reflectance in the blue and red channels and using them for remote sensing of aerosol [23]. Using the aerosol optical thickness as input, a lookup table was established based on the 6S model to carry out the atmospheric correction [24]. A practical split-window approach was used to retrieve LST from MODIS data [25].

Figure 3. Flow chart of irrigation estimation from ET, where: $\mathrm{SW}_{\mathrm{pa}}$, the maximum extractable soil water content $(\mathrm{mm}) ; \mathrm{SW}_{\mathrm{fc}}$, water content at field capacity $\left(\mathrm{m}^{3} / \mathrm{m}^{3}\right) ; \mathrm{SW}_{\mathrm{wp}}$, water content at permanent wilting point $\left(\mathrm{m}^{3} / \mathrm{m}^{3}\right)$; DP, soil depth $(\mathrm{mm})$, which is set to $800 \mathrm{~mm} ; \mathrm{SW}_{0}$, initial water content $(\mathrm{mm})$, which is set to $60 \% \mathrm{SW}_{\mathrm{pa}} ; \mathrm{SW}_{\mathrm{i}}$ and $\mathrm{SW}_{\mathrm{i}-1}$, water content at day $\mathrm{i}$ and $\mathrm{i}-1$ respectively $(\mathrm{mm}) ; \mathrm{ET}_{\mathrm{i}}$, evapotranspiration at day $\mathrm{i}(\mathrm{mm})$; $\mathrm{P}_{\mathrm{i}}$, precipitation at day $\mathrm{i}-1(\mathrm{~mm}) ; \mathrm{RO}_{\mathrm{i}}$, runoff at day ${ }_{\mathrm{i}}(\mathrm{mm}) ; \mathrm{DR}_{\mathrm{i}}$, drainage at day $(\mathrm{mm})$; $\mathrm{IA}_{\mathrm{i}}$, irrigation amount at day $(\mathrm{mm})$.

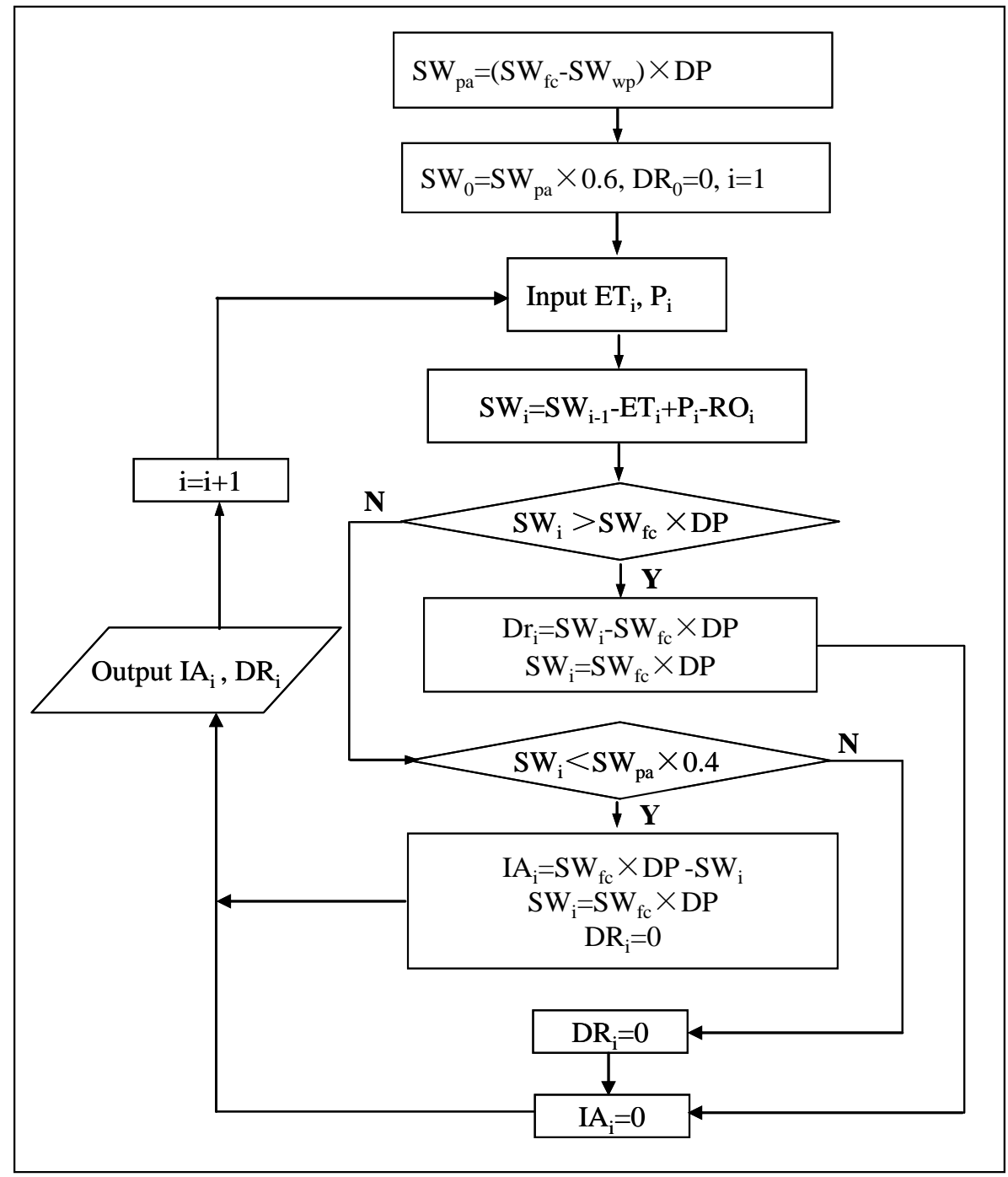


Landsat TM images with Bands 2, 3, 4 and 5 at different periods from the years 2000-2001 at a spatial scale of 1:100,000 were used to interpret land use data over the Haihe Plain. The work was done by another group of "land cover dynamic monitoring" of the Key Innovation Project (KZCX1-YW-08-03-04) of the Chinese Academy of Sciences.

\subsection{Meteorological Data}

Daily meteorological data at 83 meteorological stations, including maximum and minimum air temperature, sunshine duration, relative humidity, wind speed and air pressure (2002-2007), are collected from the National Meteorological Bureau. The variables are interpolated into daily maps at $1-\mathrm{km}$ resolution by the inverse distance squared method.

\subsection{Lysimeter Data}

Monthly ET and irrigation amount from large Lysimeter provided by Luangcheng Station (Chinese Ecosystem Research Network).

\section{Results}

\subsection{Verification}

Validation of ET estimated from ETwatch was described in the documents of [14] and [26]. According to these reports, the ET result exhibited less error than the results produced by the earlier method of constant-EF (evaporative factor). The mean absolute percent difference (MAPD) of gap-filling approach is reasonable (22.5\%), compared to MAPD produced by constant-EF (46.3\%). Alternatively, the gap-filling method used in ETWatch gives a 50\% improvement in accuracy.

The grid $\left(1 \mathrm{~km}^{2}\right)$ of farmland where the large lysimeter was installed was selected to compare its ET and IR. The simulated ET and IA for 2002 to 2007 generally matched observed ET in most of months (Figure 4), but the simulated values in a number of months in the wet season were much larger than the observed values. The error came from the different resolutions of observed and simulated data. As noted, the simulated ET and IA by remote sensing represented $1-\mathrm{km}^{2}$ grid areas, while the observed ET and IA from the lysimeter was a site-specific point value. In the study region, a $1-\mathrm{km}^{2}$ area usually consists of different crops, roads and several villages.

To evaluate the model prediction of IA at the regional scale, water use by agricultural departments in 87 counties in the Hebei Plain (more than $80 \%$ of the Haihe Plain) from 2005 to 2006 (the data are from the Yearbook of Hebei Province Water Resources) was used to compare with the simulated result. Legates and McCabe [27] recommended that a complete assessment of model performance should include at least one "goodness-of-fit" or relative error measure (e.g., E1' (modified coefficient of efficiency) or d1' (modified index of agreement)) and at least one absolute error measure (e.g., root mean square error (RMSE) or mean absolute error (MAE), with additional supporting information (e.g., a comparison between the observed and simulated mean and standard deviations). E1' or d1' was recommended to replace the determination coefficient $\left(\mathrm{R}^{2}\right)$ or Pearson's correlation coefficient $(\mathrm{P})$, because these are oversensitive to extreme values and are insensitive to additive and proportional differences between model predictions and observations. Therefore, in this paper, both correlation-related methods 
(e.g., d1') and absolute error measure (e.g., MAE) are used to evaluate the model (Table 1). The results show that the mean absolute differences between modelled and observed values in 2005, 2006 and 2007 are $17.9 \%, 1.36 \%$ and $17.8 \%$, respectively, which are all lower than $20 \%$. In 2006, the mean predicted value is very close to the observed value. Both MAE and RMSE in 2007 are higher than those in 2005 and 2006. Most of the values of the correlation related statistics, including $\mathrm{P}, \mathrm{R}^{2}$ and $\mathrm{d} 1$ for all years, are over 0.60, indicating that the modelled results were reasonable.

Figure 4. Comparison of simulated and observed monthly ET (mm) and irrigation applied (IA) (mm) from the years from 2002 to 2007.
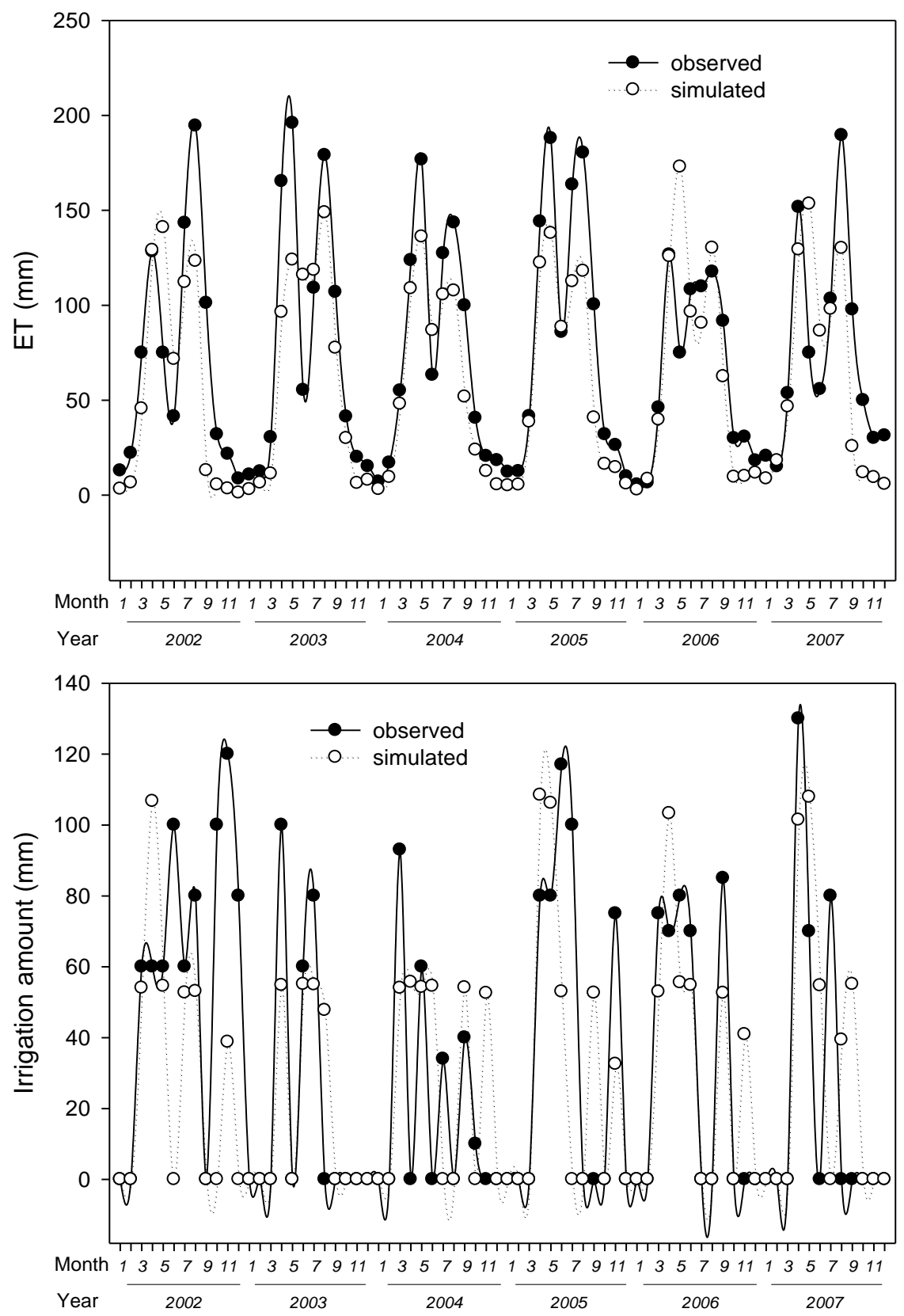
Table 1. Means and standard deviations of observed and simulated yearly irrigation amount for county of Haihe Plain for the years of 2005, 2006 and 2007, and the statistics comparing the observed and simulated values.

\begin{tabular}{|c|c|c|c|c|c|c|}
\hline & \multicolumn{2}{|c|}{2005} & \multicolumn{2}{|c|}{2006} & \multicolumn{2}{|c|}{2007} \\
\hline & Observed & Modelled & Observed & Modelled & Observed & Modelled \\
\hline Mean, mm & 240 & 224 & 295 & 299 & 246 & 202 \\
\hline Standard deviation, $\mathrm{mm}$ & 74 & 50 & 91 & 72 & 95 & 80 \\
\hline Mean absolute error, mm & \multicolumn{2}{|c|}{38.88} & \multicolumn{2}{|c|}{39.75} & \multicolumn{2}{|c|}{52.05} \\
\hline Root mean square error, mm & \multicolumn{2}{|c|}{53} & \multicolumn{2}{|c|}{55} & \multicolumn{2}{|c|}{71} \\
\hline Pearson's correlation & \multicolumn{2}{|c|}{0.73} & \multicolumn{2}{|c|}{0.80} & \multicolumn{2}{|c|}{0.81} \\
\hline Coefficient of determination & \multicolumn{2}{|c|}{0.53} & \multicolumn{2}{|c|}{0.64} & \multicolumn{2}{|c|}{0.65} \\
\hline Modified index of agreement & \multicolumn{2}{|c|}{0.61} & \multicolumn{2}{|c|}{0.68} & \multicolumn{2}{|c|}{0.68} \\
\hline
\end{tabular}

\subsection{Yearly Spatial Distribution of ET and IA}

The simulation of spatial distribution of ET in the Haihe Plain is illustrated in Figure 5. There is a general pattern for the modelled annual ET distributions. The regions along Taihang Mountain (western Hebei Province) and in Shandong Province have the highest ET, with a range of 650-1050 $\mathrm{mm}$ in most years, while the regions located in the low plain close to Bohai Sea have the lowest ET, with less than $500 \mathrm{~mm}$. The north and middle regions indicate moderate ET, with a range of 500-700 mm.

Figure 5. Spatial distribution of yearly ET in Haihe Plain during 2002-2007.

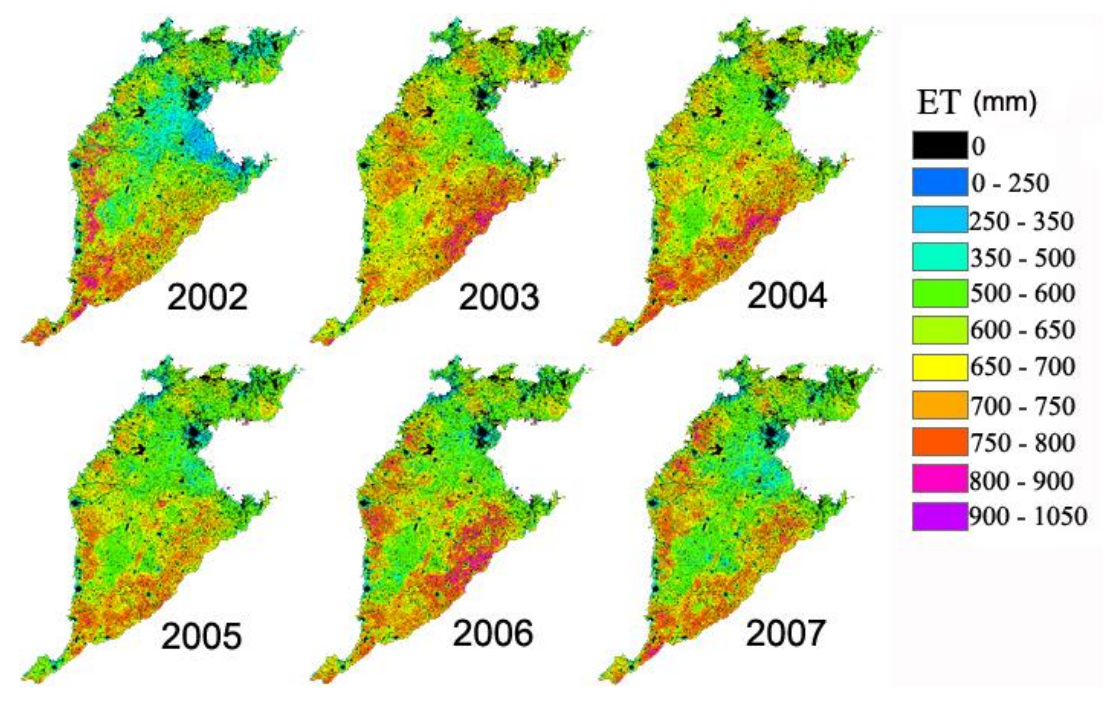

The spatial pattern of IA (Figure 6) is similar to that of ET. The IA in the piedmont regions of Taihang Mountain and regions in Shandong Province are higher with the range of 200-600 mm; while the IA in the low plain and middle part of the south region is lower, with a range of $0-350 \mathrm{~mm}$. The reason for the higher IA in the piedmont region and Shandong Province is that these regions have better water resources: relatively plentiful groundwater conditions, due to ample recharge from the mountain area for the piedmont region, and ample surface water for the regions in Shandong Province. With better water supplies and also fertile soil conditions, a winter wheat-summer maize planting 
system is used in these regions. With the intensive planting pattern and high water consuming crop (winter wheat), the ET and IA are higher in these regions. In contrast is the lower plain, where water conditions are worse for winter crops, due to a shortage of fresh water. However, even in a dry year, such as 2002, the IA is very low. The reason for the lower IA in the middle part of the southern region is its greater cotton cultivation areas and fewer winter crops. Cotton is a drought-resistant crop and grows through the rainy reason. Therefore, in the rainy or normal years, such as 2003, 2004, 2005 and 2007, IA is lower in the region. However, for very dry years, such as 2002 and 2006, some quantity of irrigation is still required.

Figure 6. Spatial distribution of yearly irrigation applied (IA) (mm) in Haihe Plain during 2002-2007.

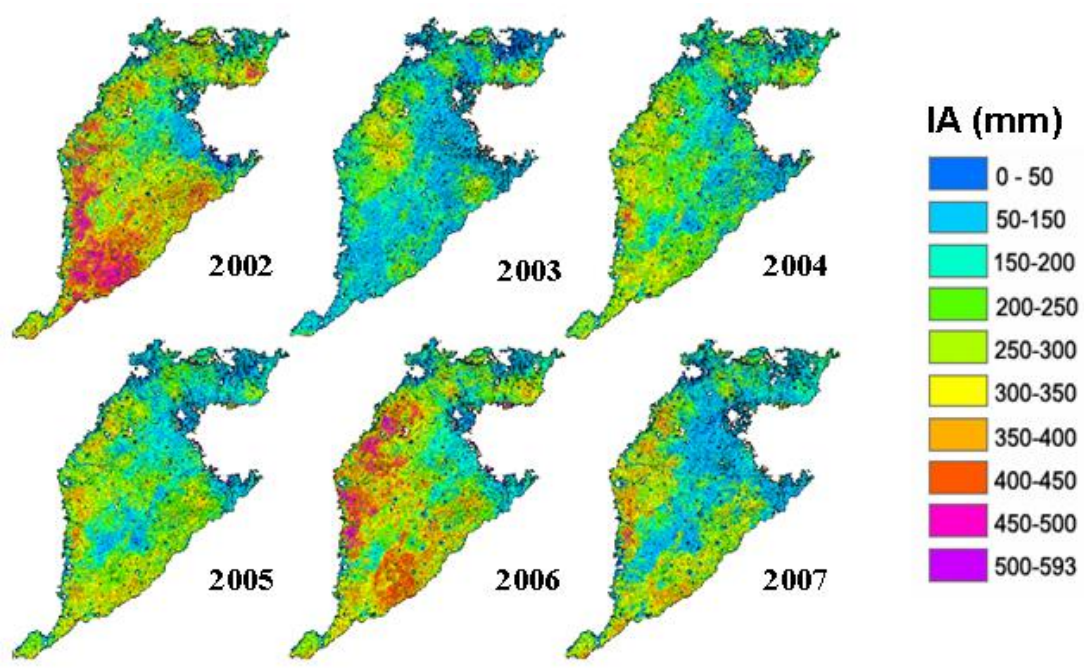

Figure 7. Yearly precipitation (mm), ET (mm) and irrigation applied (mm) during 2002-2007.

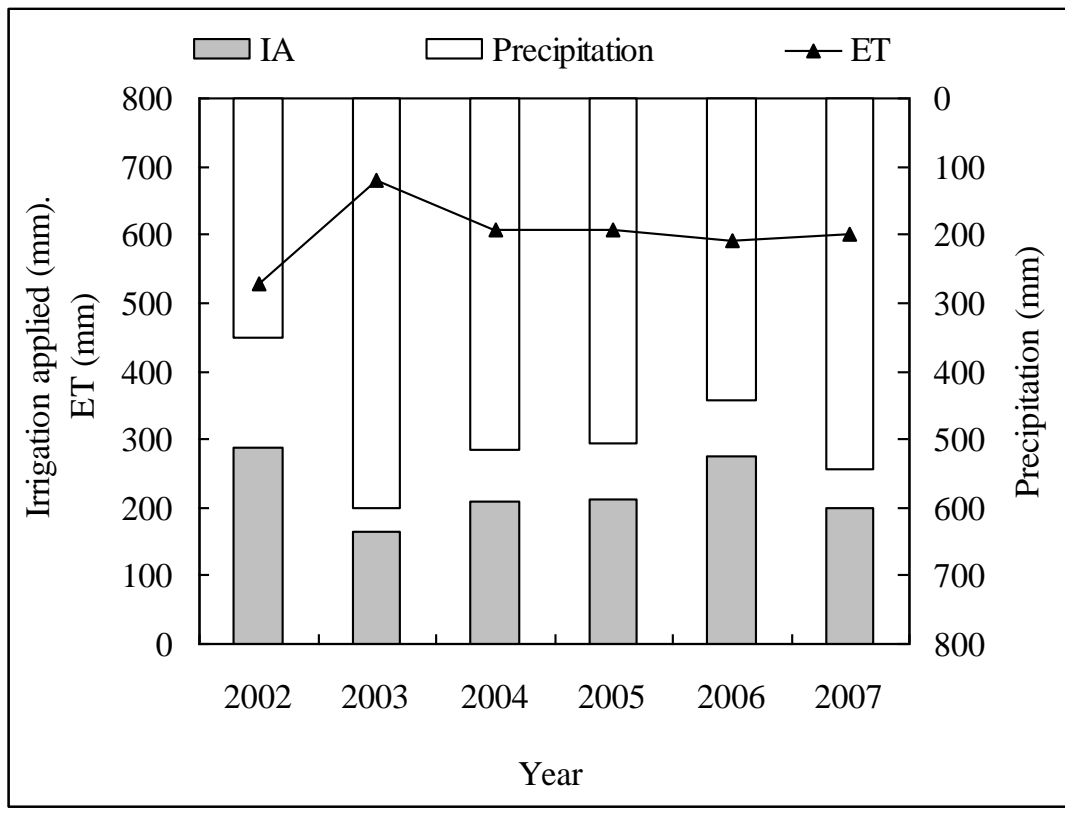

Averaged across the whole region, yearly ET and IA vary from $527 \mathrm{~mm}$ to $679 \mathrm{~mm}$ and $166 \mathrm{~mm}$ to $289 \mathrm{~mm}$, with mean values of $602 \mathrm{~mm}$ and $225 \mathrm{~mm}$, respectively, from 2002 to 2007 (Figure 7). 
Yearly variations in ET and IA are highly related to precipitation, which varies from $351 \mathrm{~mm}$ to $601 \mathrm{~mm}$, with a mean value of $493 \mathrm{~mm}$ from 2002 to 2007. ET is positively correlated to precipitation and IA is negatively correlated to it. For example, in 2003, the precipitation is as high as $601 \mathrm{~mm}$; accordingly, the ET is the highest $(679 \mathrm{~mm})$; however, the IA is lowest $(225 \mathrm{~mm})$ in that year.

\subsection{Monthly Spatial Distribution of ET and IA}

The monthly distributions of ET and IA are simulated for each year of the study (Figures 8 and 9). Figure 8 illustrates that the months of May, July and August have the largest ET. June has comparatively lower ET, because it is a period when the spring crop is harvested and the summer crop begins to be planted. All these months have higher temperature and precipitation. The highest ETs in May are located in the western region along the Taihang Mountain piedmont. Higher ET in July and August are also distributed in the middle part of the study area. Figure 9 illustrates the monthly spatial distribution of IA. The pattern of the spatial distribution of IA in months with less precipitation, such as April and May, is similar to that of ET. Contrarily, the spatial distribution of IA in months with more precipitation is different from that of ET, because the precipitation provided required water. Averaged monthly ET, IA and precipitation are indicated in Figure 10. The three months with the highest ETs are May, July and August; whereas June, July and August are the three months with the highest precipitation. The three months with the highest IA are April, May and September.

Figure 8. Spatial distribution of monthly irrigation applied in Haihe Plain during 2002-2007.

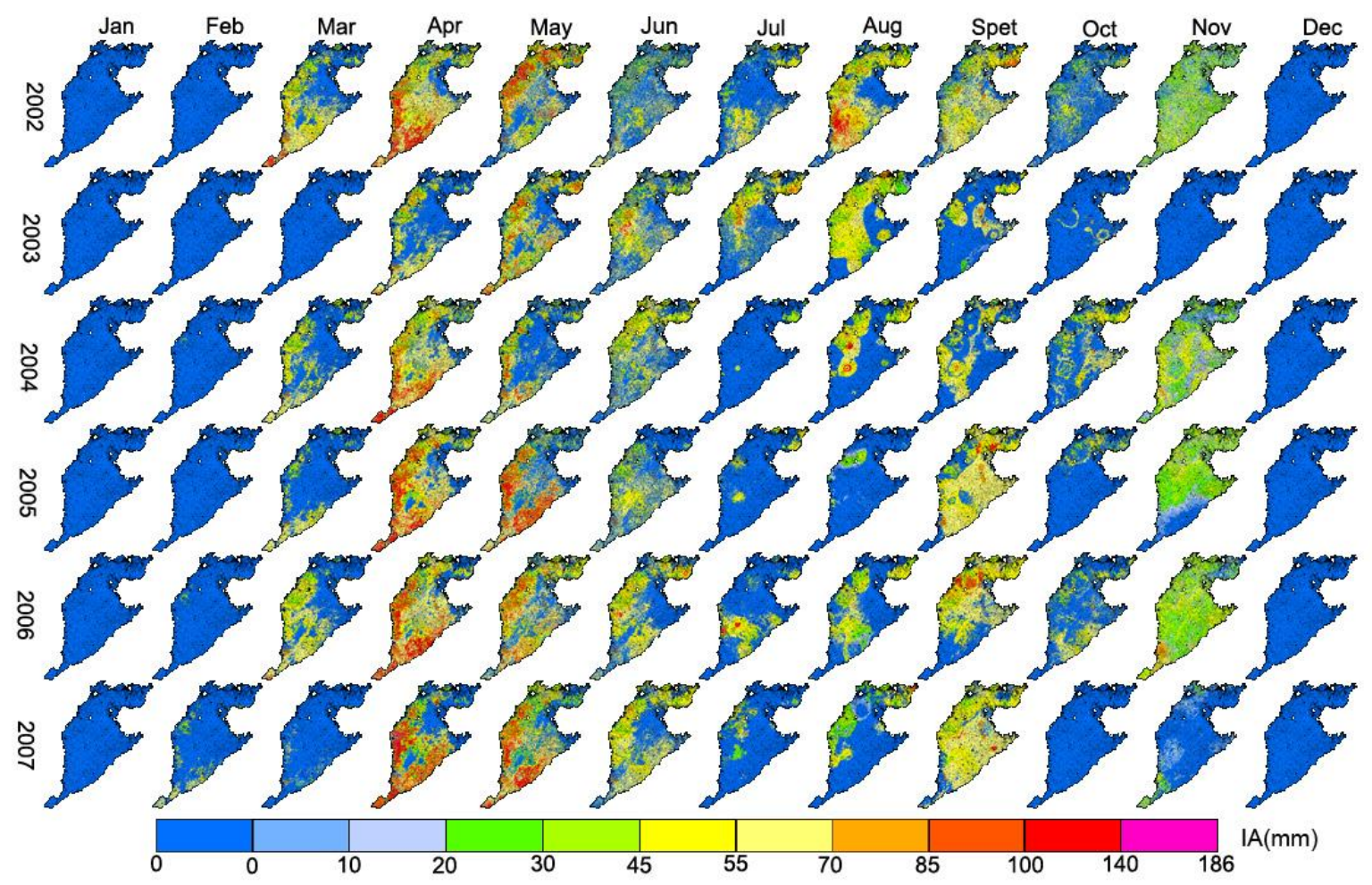


Figure 9. Spatial distribution of monthly ET in Haihe Plain during 2002-2007.

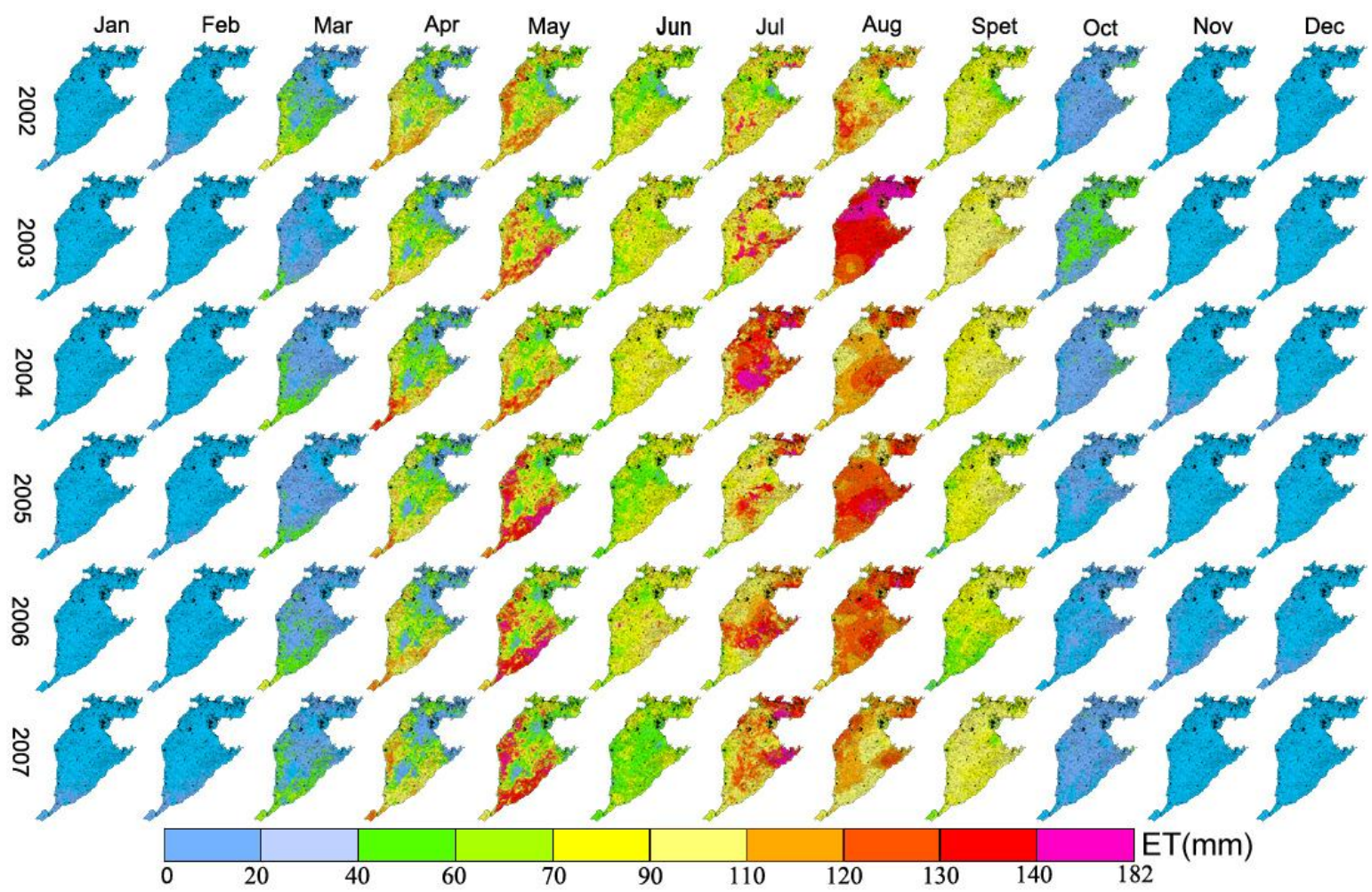

Figure 10. Monthly precipitation $(\mathrm{mm})$, ET $(\mathrm{mm})$ and irrigation applied (IA) $(\mathrm{mm})$ averaged across 2002-2007.

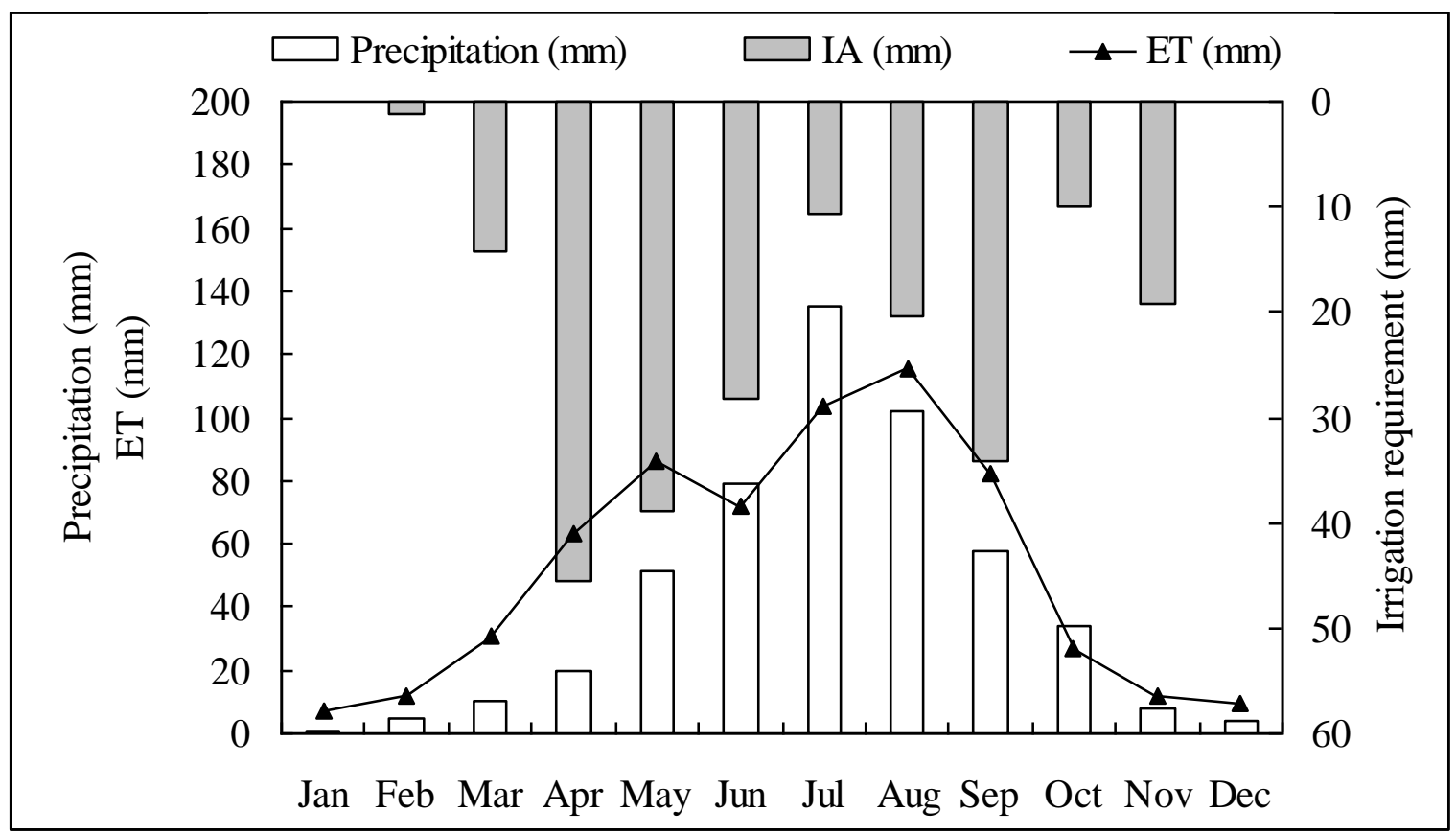

\subsection{Reallocation of Water Resources after SNWT Project in Hebei Plain}

The RS results for irrigation requirements are used to evaluate the future water resource redistribution in the Hebei Plain after the SNWT project. Since precipitation is insufficient to recharge 
groundwater in the North China Plain [28], SNWT has been under construction to stop groundwater table decline. Figure 11 indicates the planned amounts of water transfer by middle and east routes to different districts of Hebei Plain. It shows that except for the capital city Shijiazhuang, which is to receive a large relative share of transfer water, some other districts may be far from satisfied in meeting their irrigation requirements. Especially for Cangzhou and Hengshui, these two districts have the worst water conditions: less available surface water, rapid depletion of confined aquifers and brackish unconfined aquifer water qualities [29]. These two districts appear to require more irrigation water than officially indicated. Therefore, this study suggests more water could be distributed to these two regions to remedy their deficits.

Figure 11. The required irrigation amount $\left(10^{9} \mathrm{~m}^{3}\right.$ or $\left.\mathrm{km}^{3}\right)$ estimated by remote sensing models, district agricultural water use (official data) and planned amount of water to be allocated from the South-North Water Transfer (SNWT) project in different districts of Hebei Plain.

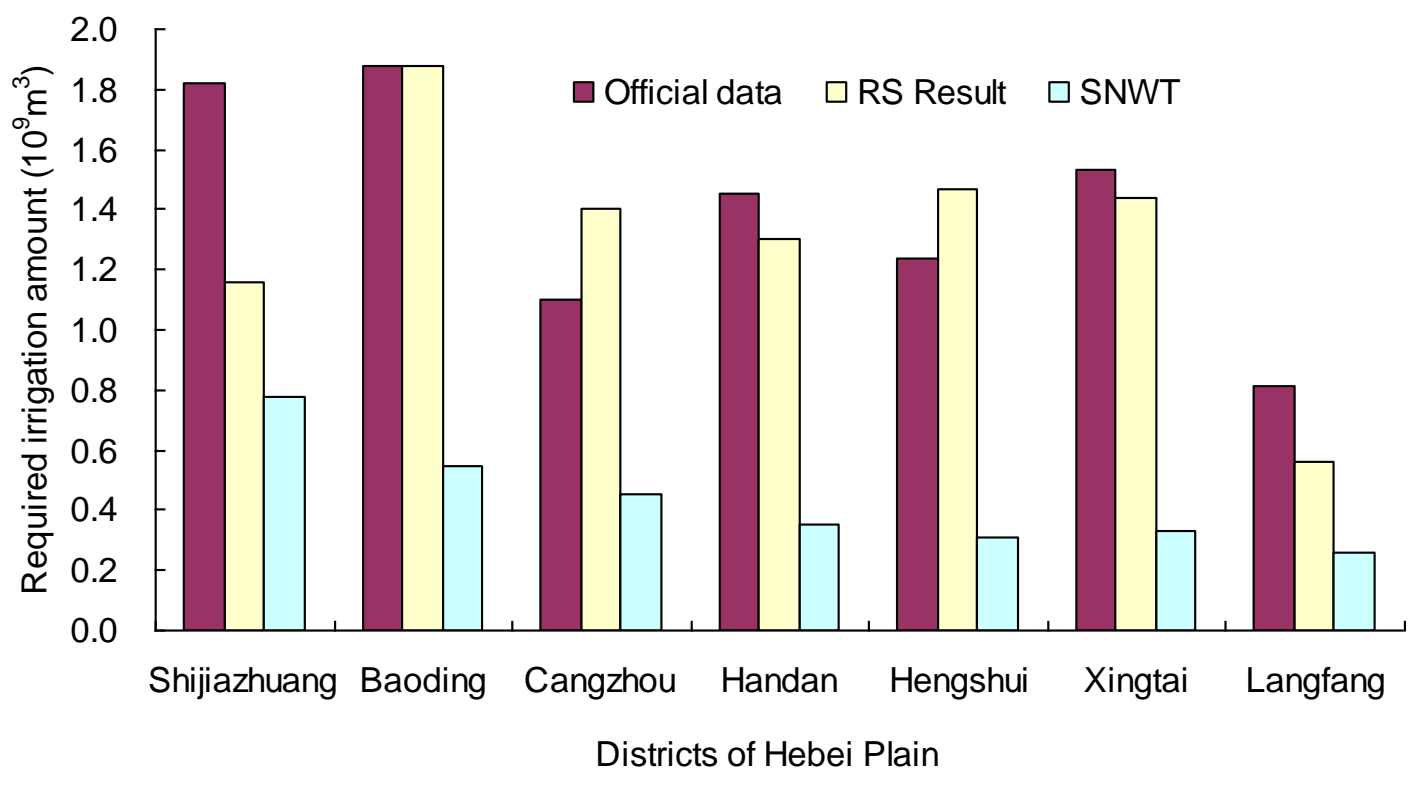

\section{Discussion}

\subsection{Comparison with Contemporary Studies}

Both the ET and IA simulated results from our study are reasonable when compared to the results from contemporary studies. The average ET estimated by ETWatch for farmland of Haihe Plain during 2002-2007 is $602 \mathrm{~mm}$, which is very similar to the result from Li [30], who demonstrated that the ET of farmland in Haihe Plain was 600-660 mm, by using a water balance method. They are also validated by the results from $\mathrm{Yu}$ [31], who concluded that ET in irrigation land is above $660 \mathrm{~mm}$ and that in rain-fed land, it is $400 \mathrm{~mm}$. However, the latter result is low when compared to other site-specific experiments, most of which show ET under a winter-wheat and summer-maize rotation system is about 800-900 mm [20]. The differences were, at least partially, due to ETWatch representing land and water use on regional scales, which include roads, trees and villages. 
The percentage differences between simulated and observed IA results are under $20 \%$ (Table 1). However, they show a lower trend, which is better explained by the difference between the simulated applied irrigation and actual applied irrigation by farmer. The irrigation applied, estimated here by modelling, is based on an optimum state of soil water. However, the statistical data (Table 1) is the gross irrigation, including the irrigation loss, including drainage infiltrating to the groundwater. In practice, farmers determine the amounts of irrigation water largely by experience and often apply more water than required by our modelling criteria, which only calls for refilling to field capacity. With the aid of crop growth modelling [32], an earlier result was that the irrigation applied to Hebei Plain (most parts of Haihe Plain) averaged $348 \mathrm{~mm}$ from 1986 to 2006, which is higher than the result in this study. This is inferred from 8.7 billion $\mathrm{m}^{3}$ of agricultural water use in official data by the Water Resources Department of Hebei Province (WRDHP) in Yang et al. [32], that irrigation applications averaged $279 \mathrm{~mm}$ from 1986 to 2006. The irrigation applied of $225 \mathrm{~mm}$ (for Hebei Plain) in this study is lower than either the statistical data of $279 \mathrm{~mm}$ or the crop modelling result of $348 \mathrm{~mm}$ from Yang et al. [32]. However, the site result of $328 \mathrm{~mm}$ in Luancheng Station (experimentally observed result from the Lucheng Station average from 2002 to 2007) is closer to $348 \mathrm{~mm}$ of the crop modelling result. This indicates that the crop modelling is more site-specific, while the results of this study are more reflective of regional characteristics. Moreover, the present study has much higher spatial resolution $\left(1 \mathrm{~km}^{2}\right)$ compared to former studies with crop growth models at resolutions averaging across county areas of about $1100 \mathrm{~km}^{2}$.

\subsection{Bias Analysis}

Since the IA estimation is based on a simple water balance model, it still needs further improvement. Our simplifying assumption is that the irrigation triggering mechanism (when soil water content is less than $40 \%$ of field capacity) is the same throughout the study area. It does not take crop type, irrigation application practice, weather conditions, etc., into account. Some error is inevitable under this hypothesis. For example, the soil water deficiencies of different crops for triggering irrigation may not be the same, because different crops have different drought-tolerance potentials. Thus, errors in irrigation frequency will occur. Moreover, irrigation quotas should be different under different irrigation application practices, such as dripping, spraying and furrowing, other than simply to differences between soil water content when irrigation is triggered and field capacity. Though error will occur in irrigation frequency and quota, the total irrigation amount will keep balanced with ET, because the model is based on the soil water balance. However, the error in total irrigation estimates will occur under the condition when precipitation takes place on days closely following irrigation, which will be modelled as increased water drainage down to groundwater. In fact, farmers decide whether to irrigate depending on short-term rainfall forecasts and current soil moisture status. The present study provides a simple method to estimate spatial and temporal distributions of irrigation requirements. As for the exact irrigation frequency and volumes for farmer, there is a need for further research. Further work should be focused on more reasonable ways to calculate irrigation triggering time and quota by including consideration of the water use characteristics of different crop types and different irrigation application methods. 


\subsection{Suggestion for the Sustainability of Water Resources}

Intensive agricultural production in Haihe Basin, especially Hebei Plain, makes the water shortage situation more and more pressing. As 70\% of irrigation comes from groundwater, the groundwater table has declined drastically over several decades. According to the report from Yang et al. [33], an approximate $100-\mathrm{mm}$ irrigation application in cultivated land leads to about a 640-mm groundwater decline. However, groundwater recharge is not sufficiently met by precipitation. Han et al. [28] reported that precipitation recharge is only expected when a single or successive rainfall are in excess of the minimum amount of $170 \mathrm{~mm}$, a very rare condition in the piedmont region (Baoding, Shijiazhuang, Xingtai and Handan districts). While in the coastal and middle area, Cangzhou and Hengshui district, groundwater age has been found to exceed 10,000 years, this means there is only a remote possibility of confined aquifer recharge in these districts [34].

Though SNWT aims to alleviate the water shortage problem, it may not completely meet water demand in the study area (Figure 11). More strategies should be applied to stop ground water decline. One of the ideal ways is to change the current double cropping system, winter wheat and summer corn, to a single cropping system, corn. Winter wheat is the higher irrigation crop, because it is sown in the dry season. However, the Chinese population is large and needs more food to feed itself. Therefore, completely abandoning irrigated winter wheat production is impossible in the real world. The more reasonable and feasible approach is to develop water-saving agricultural technologies. This should be promoted by decision-makers, irrigation planners and agro-scientists. Hu et al. [35] suggested that a $29.2 \%$ or $135.7 \mathrm{~mm}$ reduction in irrigation could stop groundwater drawdown in the plain. An additional $10 \%$ reduction in irrigation pumping (i.e., a total of $39.2 \%$ or $182.1 \mathrm{~mm}$ ) would induce groundwater recovery and restoration to the pre-development hydrologic conditions of 1956 in about 74 years. Total yield loss for wheat and maize under the appropriate irrigation timing and rate would be less than $10 \%$. However, this should be supplemented with strong political will, water-saving incentives and water policy regulation and enforcement. The present study calculated IA based upon soil water deficits, without regard to the values of different crops received by farmers in the various districts, which translate into economic incentives for them. Where water quotas are limited, farmers will have incentives to avoid waste by putting available water to its best possible use in their farms. A market for water can provide further incentives for the most economically efficient use of this scarce resource across different production zones.

\section{Conclusions}

An irrigation applied (IA) estimation model together with an ET-calculating model (ETWatch) was set up to simulate the spatial distribution of IA in the Haihe Plain during the years from 2002-2007. Through comparison with the regional observed values, simulated IA shows a reasonable result with the correlation related statistics, including P, R2 and d1, all above 0.60 . The present model is verified as an effective and feasible approach to simulate regional irrigation requirements and has the advantage of better reflecting local regional characteristics and at a higher resolution than the limited site-specific results upon which earlier catchment-wide estimates have been made. The simulated results show that annual ET and IA vary from $527 \mathrm{~mm}$ to $679 \mathrm{~mm}$ and $166 \mathrm{~mm}$ to $289 \mathrm{~mm}$, with 
average values of $602 \mathrm{~mm}$ and $225 \mathrm{~mm}$, respectively, over the years from 2002 to 2007. Regions along Taihang Mountain and areas in Hebei Province have the highest ET and IA, with major problems in water resource sustainability, because of their intensive agricultural production and declining groundwater tables, even with new water expected from the SNWT project. Besides the need for more SNWT water for this area, agricultural water saving techniques are urgently required to stop groundwater decline. This study supports further development work to better integrate RS techniques, land use information ground-truthing and tools, such as the ET-calculating model ETWatch. Such an advance could provide a basis for the better understanding of the inescapable real-world trade-offs among competing economic, social and environmental goals.

\section{Acknowledgment}

Financial support is by the National 973 Project (2010CB951002), the International Collaborative Project (2012DFG90290) of the Ministry of Science and Technology and the Natural Science Foundation Committee (41240010). We thank the supporting staff for the data collection and organizational cooperation.

\section{Author Contributions}

Yanmin Yang, Yonghui Yang, Deli Liu and Tom Nordblom are principal authors contributing at irrigation estimation. The order of the authors reflects their level of contribution. Yanmin Yang and Yonghui Yang have written the majority of the manuscript and Deli Liu and Tom Nordblom are responsible for the paper revision in English. Bingfang $\mathrm{Wu}$ and Nana Yan contributed in the ET inversion by ET calculation model (ETWatch).

\section{Conflicts of Interest}

The authors declare no conflict of interest.

\section{Reference}

1. Ahmad, M.D.; Turral, H.; Nazeer, A. Diagnosing irrigation performance and water productivity through satellite remote sensing and secondary data in a large irrigation system of Pakistan. Agric. Water Manag. 2009, 96, 551-564.

2. Wriedt, G.; van der Velde, M.; Aloe, A.; Bouraoui, F. Estimating irrigation water requirements in Europe. J. Hydrol. 2009, 373, 527-544.

3. Boken, V.K.; Hoogenboom, G.; Hook, J.E.; Thomas, D.L.; Guerra, L.C.; Harrison, K.A. Agricultural water use estimation using geospatial modeling and a geographic information system. Agric. Water Manag. 2004, 67, 185-199.

4. Allen, R.G. Using the FAO-56 dual crop coefficient method over an irrigated region as part of an evapotranspiration intercomparison study. J. Hydrol. 2000, 229, 27-41.

5. Knox, J.W.; Weatherhead, K.; Loris, A.A.R. Assessing water requirements for irrigated agriculture in Scotland. Water Int. 2007, 32, 133-144. 
6. Ozdogan, M.; Woodcock, C.E.; Salvucci, G.D.; Demir, H. Changes in summer irrigated crop area and water use in Southeastern Turkey from 1993 to 2002: Implications for current and future water resources. Water Resour. Manag. 2006, 20, 467-488.

7. Leenhardt, D.; Trouvat, J.L.; Gonzales, G.; Perarnaud, V.; Prats, S.; Bergez, J.E. Estimating irrigation demand for water management on a regional scale II. Validation of ADEAUMIS. Agric. Water Manag. 2004, 68, 233-250.

8. Ines, A.V.M.; Das Gupta, A.; Loof, R. Application of GIS and crop growth models in estimating water productivity. Agric. Water Manag. 2002, 54, 205-225.

9. Guerra, L.C.; Garcia y Garcia, A.; Hook, J.E.; Harrison, K.A.; Thomas, D.L.; Stooksbury, D.E.; Hoogenboom, G. Irrigation water use estimates based on crop simulation models and kriging. Agric. Water Manag. 2007, 89, 199-207.

10. Liu, J.G.; Williams, J.R.; Zehnder, A.J.B.; Yang, H. GEPIC-Modelling wheat yield and crop water productivity with high resolution on a global scale. Agric. Syst. 2007, 94, 478-493.

11. Hadria, R.; Duchemin, B.; Baup, F.; Le Toan, T.; Bouvet, A.; Dedieu, G.; Le Page, M. Combined use of optical and radar satellite data for the detection of tillage and irrigation operations: Case study in Central Morocco. Agric. Water Manag. 2009, 96, 1120-1127.

12. Ines, A.V.M.; Honda, K.; Das Gupta, A.; Droogers, P.; Clemente, R.S. Combining remote sensing-simulation modeling and genetic algorithm optimization to explore water management options in irrigated agriculture. Agric. Water Manag. 2006, 83, 221-232.

13. Bastiaanssen, W.G.M.; Noordman, E.J.M.; Pelgrum, H.; Davids, G.; Thoreson, B.P.; Allen, R.G. SEBAL model with remotely sensed data to improve water-resources management under actual field conditions. J. Irrig. Drain. Eng. Asce 2005, 131, 85-93.

14. Wu, B.; Xiong, J.; Yan, N.; Yang, L.; Du, X. ETWatch for monitoring regional evapotranspiration with remote sensing. Adv. Water Sci. 2008, 19, 671-678.

15. Yang, G.Y.; Wang, Z.S.; Wagn, H.; Jia, Y.W. Potential evapotranspiration evolution rule and its sensitivity analysis in Haihe River Basin. Adv. Water Sci. 2009, 20, 409-415.

16. Zheng, S.; Li, X. Study on water resources and its sustainable use in the Haihe River Basin. South North Water Trans. Water Sci. Tech. 2009, 7, 45-77.

17. Liu, C.M. Environmental issues and the south-north water transfer scheme. China Q. 1998, 899-910.

18. Wu, B.; Yan, N.; Xiong, J.; Bastiaanssen, W.G.M.; Zhu, W.; Stein, A. Validation of ETWatch using field measurements at diverse landscapes: A case study in Hai Basin of China. J. Hydrol. 2012, 436, 67-80.

19. Wu, B.X.; Xiong, J.; Yan, N.; Yang, L. ETWatch: An Operational ET Monitoring System with Remote Sensing. In Proceedings of the 2008 ISPRS Workshop on Geo-information and Decision Support Systems, Tehran, Iran, 6-7 January 2008.

20. Sun, H.; Shen, Y.; Yu, Q.; Flerchinger, G.N.; Zhang, Y.; Liu, C.; Zhang, X. Effect of precipitation change on water balance and WUE of the winter wheat-summer maize rotation in the North China Plain. Agric. Water Manag. 2010, 97, 1139-1145.

21. Saxton, K.; Rawls, W. Soil water characteristic estimates by texture and organic matter for hydrologic solutions Soil Sci. Soc. Am. J. 2006, 70, 1569-1578. 
22. LAADS Web: Level 1 and Atmosphere Archive and Distribution System. Available online: http://ladsweb.nascom.nasa.gov/data/search.html (accessed 3 March 2013).

23. Kaufman, Y.J.W.; Remer, L.A.; Gao, B.; Li, R.; Flynn, L. The MODIS $21 \mu \mathrm{m}$ channel-Correlation with visible reflectance for use in remote sensing of aerosol. IEEE Trans. Geosci. Remote Sens. 1997, 35, 1-13.

24. Vermote, E.F.; Tanre, D.; Deuze, J.L.; Herman, M.; Morcrette, J.J. Second simulation of the satellite signal in the solar spectrum, 6S: An overview. IEEE Trans. Geosci. Remote Sens. 1997, 35, 675-686.

25. Mao, K.; Qin, Z.; Shi, J.; Gong, P. A practical split-window algorithm for retrieving land-surface temperature from MODIS data. Int. J. Remote Sens. 2005, 26, 3181-3204.

26. Xiong, J.; Wu, B.; Yan, N.; Zeng, Y.; Liu, S. Estimation and validation of land surface evaporation using remote sensing and meteorological data in North China. IEEE J. Sel. Top. Appl. Earth Obs. Remote Sens. 2010, 3, 337-344.

27. Legates, D.R.; McCabe, G.J. Evaluating the use of "goodness-of-fit" measures in hydrologic and hydroclimatic model validation. Water Resour. Res. 1999, 35, 233-241.

28. Han, S.; Yang, Y.; Lei, Y.; Tang, C.; Moiwo, J.P. Seasonal groundwater storage anomaly and vadose zone soil moisture as indicators of precipitation recharge in the piedmont region of Taihang Mountain, North China Plain. Hydrol. Res. 2008, 39, 479-495.

29. Water Resources Department of Hebei Province. Yearbook of Hebei Province Water Resources Statistic 1986-2006; Hebei Province Statistical Publishing House: Shijiazhuang, China, 2007. (In Chinese)

30. Li, Y.D. Controlling ET to ensure the sustainable exploitation of water resources in Haihe Catchment. Hydrol. Haihe Catch. 2007, 1, 4-8.

31. Yu, W.D. Water balance and water resources sustainable development in Haihe River Basin. J. China Hydrol. 2008, 28, 79-82.

32. Yang, Y.; Yang, Y.; Moiwo, J.P.; Hu, Y. Estimation of irrigation requirement for sustainable water resources reallocation in North China. Agric. Water Manag. 2010, 97, 1711-1721.

33. Yang, Y.; Watanabe, M.; Zhang, X.; Hao, X.; Zhang, J. Estimation of groundwater use by crop production simulated by DSSAT-wheat and DSSAT-maize models in the piedmont region of the North China Plain. Hydrol. Process. 2006, 20, 2787-2802.

34. Water Resources Department of Hebei Province. Report on Exploitation Planning for Hebei Provincial Groundwater Resources; Hebei Province Statistical Publishing House: Shijiazhuang, China, 1998. (In Chinese)

35. Hu, Y.; Moiwo, J.P.; Yang, Y.; Han, S.; Yang, Y. Agricultural water-saving and sustainable groundwater management in Shijiazhuang Irrigation District, North China Plain. J. Hydrol. 2010, 393, 219-232.

(C) 2014 by the authors; licensee MDPI, Basel, Switzerland. This article is an open access article distributed under the terms and conditions of the Creative Commons Attribution license (http://creativecommons.org/licenses/by/3.0/). 